\title{
Cofradías de Caballeros en la Castilla del quinientos. El caso de Ávila
}

\author{
José LUIS MARTíN
}

\section{CABALLEROS Y CABALLEROS ANDANTES}

Soldado en Lepanto, bien pudo Miguel de Cervantes contarse entre los «arbitrantes» o arbitristas que aconsejaron a Felipe II, en 1572, que ordenara la creación en cada ciudad y villa de una cofradía de caballeros hidalgos que, con el pretexto de celebrar la festividad de su santo patrón, practicaran los juegos de la guerra (torneos, justas, correr la sortija o las cañas...) y se entrenaran para mejor defender el reino si algún día era atacado. Años más tarde, don Quijote hará suyo, a su manera, el arbitrio ofrecido al monarca español: «¿Hay más sino mandar su Majestad por público pregón que se junten en la Corte para un día señalado todos los caballeros andantes que vagan por España, que aunque no viniesen sino media docena, tal podría venir entre ellos, que solo bastase a destruir toda la potestad del turco?»?

El rey no convocó a los caballeros andantes para hacer frente al turco; Felipe II sí hizo caso a sus consejeros y se dirigió a las ciudades y villas del reino para exponerles la idea y pedir consejo práctico para llevarla a cabo. El monarca pide que se reúnan los regidores y caballeros, discutan la propuesta, decidan la advocación de la cofradía, redacten sus ordenanzas, señalen cómo se ve la creación en el lugar, qué apoyos precisan para que la cofradía funcione; en qué puede colaborar el monarca y qué está dispuesta a poner la villa de sus bienes de propios; qué ejercicios piensan hacer, y cualquier otra sugerencia que lleve al fin propuesto: «que los caballeros y nobleza estén armados, encavalgados, usados y exerçitados".

\footnotetext{
Utilizo la edición de Espasa Calpe, Austral²1, Madrid 1960, pág. 354.
} 
Como no podía ser menos, al recibir la real cédula, los concejos se apresuraron a obedecer la orden, se reunieron los regidores con o sin los caballeros, tomaron sus acuerdos y los comunicaron al monarca, a veces, acompañados de un escrito del corregidor de la villa o ciudad que actúa en este caso como nombre del monarca y hace cuanto está en su mano para que los deseos del monarca se conviertan en realidad; los informes fueron encuadernados en un legajo que se conserva en el Archivo General de Simancas, Sección Diversos de Castilla, leg. 25, fol. $1^{2}$. Además de escribir a los concejos, Felipe II se dirigió a los nobles y eclesiásticos pidiendo información sobre el estado de las fortalezas, hombres a su cargo, armas de las que disponían... ${ }^{3}$.

La gran cantidad de información suministrada por concejos, corregidores, nobles y eclesiásticos impide analizarla con detalle en un trabajo de esta naturaleza -en el que nos limitaremos a estudiar los datos facilitados desde Arévalo, Ávila y Madrigal-, pero sí es posible adelantar alguna conclusión de interés: en casi todos los casos el patrono de las cofradías existentes con anterioridad o creadas a raíz de la iniciativa real es el apóstol Santiago, el Santiago Matamoros que jamás mató un moro según ha probado en diversas ocasiones el abulense Claudio SánchezAlbornoz cuyas palabras cierran esta obra como homenaje al cumplirse el centenario de su nacimiento el 7 de abril ${ }^{4}$.

La segunda conclusión que ahora interesa destacar es el interés de los concejos y de sus dirigentes por resucitar o crear cofradías de caballeros, prueba evidente de la atracción que los caballeros o sus fiestas ejercían sobre los habitantes de villas y ciudades; en una primera aproximación podría pensarse que si se crean cofradías se debe a la presión del monarca, pero ésta se ejerce sólo sobre los concejos de la Corona de Castilla y la revitalización de las cofradías se observa igualmente, utilizando argumentos semejantes a los de Felipe II, en la Corona de Aragón donde se crean o rehacen cofradías como la de Sant Jordi de Barcelona, refformada el 8 de febrero de 1565.

2 El legajo carece de paginación por lo que he dado un número a las fotocopias utilizadas para que, al menos, sirva de referencia. El fol. 1 ocupa 714 págs.

3 El fol. 2 del mismo legajo ocupa las páginas 715-806 (Respuestas de los Grandes y Señores del Reino) y el 3 (págs. 807-809) es el Testimonio en que constan las armas y pertrechos de guerra que había en el estado de Oropesa. 29 de febrero de 1573. Las respuestas de los eclesiásticos están en el fol. 1 al lado de las villas y ciudades.

${ }^{4}$ La coincidencia del Centenario y del Año Jacobeo ha llevado a la Fundación SánchezAlbornoz a buscar la reedición de los artículos de tema jacobeo de don Claudio en una obra que lleva por título: Santiago, hechura de España. 
El preámbulo de sus ordenanzas coincide con el arbitrio que siete años más tarde se ofrecerá a Felipe II:

“Considerando y viendo que el ejercicio militar es, humanamente, el mejor y más noble de todos pues sirve de protección y conservación del bien común y es el brazo derecho de la justicia, y siendo Cataluña la tierra donde más necesario es ejercitarse en dichas prácticas, por tener tan amplias fronteras por mar y por tierra, como se ha visto en otros tiempos y no hace mucho cuando los caballeros se han visto obligados a defender la frontera; y para imitar a sus antepasados de gloriosa memoria y seguir sus ejemplos, tan gloriosos que superan a todos los de su tiempo, por esto y por muchas otras razones que podrían citarse y se dejan para no ser prolijos en demasía, ordenaron celebrar cada año, el domingo después de la fiesta de San Jorge, una justa de guerra; un torneo a caballo o a pie cada año, con intervención de cuatro cuadrillas con seis caballeros en cada una... ${ }^{5}$.

He mencionado la cofradía de Barcelona, tan alejada de las tierras castellanas, porque, aunque no resulte fácil ver el nexo entre la cofradía de Sant Jordi y las de Santiago, Felipe II es el punto de unión de una y otras al mismo tiempo que uno de los artífices de la «refundación»o «reforma» de las cofradías caballerescas; el monarca español pudo ver la importancia de los «juegos" como preparación para la guerra durante su estancia en Barcelona en 1564: ante la visita del monarca, la ciudad acuerda que «si por todos los demás reyes de inmortal memoria la ciudad ha acostumbrado y acostumbra celebrar fiestas, con mayor motivo ha de hacerse por la magestad del rey nuestro señor, pues es mayor señor y de mayor imperio y señoría de lo que nunca fueron los reyes de Aragón, y así es preciso que por su bienaventurada venida se muestre el mayor contento y alegría que nunca se usó en casos semejantes" ${ }^{6}$, contento y alegría manifestados, entre otras cosas, en la celebración de un juego de armas en la Plaza del Rey donde, según Durán i Sanpere «se construyó un castillo de madera con la pretensión de parecerse al de Salses, rodeado de murallas y con grandes torres. Ante el castillo, a caballo y armado con armadura de oro, estaba San Jorge en actitud de combatir al dragón. A su lado se veía una hermosa doncella. Esta representación, que pone de relieve la intervención de la Generalitat, fue completada con

\footnotetext{
5 Ha estudiado la fundación y ordenanzas de esta cofradía DuRÁn I SANPERE, A., Barcelona i la seva Història, 2. Barcelona 1973, págs. 171-259. Los estatutos y ordenanzas se encuentran en el Archivo Histórico de la Ciudad de Barcelona y en el Archivo de la Corona de Aragón; he utilizado y traducido el texio conservado en el archivo municipal, Manuscritos, B. 64; en otros casos sigo la lectura realizada por Durán i Sanpere en la obra citada.

6 DURÁN, op. cit., págs. 192-193.
} 
un combate contra el castillo y sus defensas. El rey lo contemplaba desde una ventana del palacio" ?

La vistosidad y efectividad del juego de armas de Barcelona pudo influir en la decisión de Felipe II de resucitar o activar las cofradías de caballeros en las ciudades y villas de Castilla, y es seguro que esta decisión influyó, a su vez, en la organización de la cofradía de Sant Jordi, cuyas ordinacions fueron reformadas en 1573 por razones que recuerdan, a veces literalmente, las esgrimidas por el monarca en la real cédula enviada a los concejos y reproducida más adelante, aunque, justo es reconocerlo, los catalanes tienen mayor sentido histórico y se remontan hasta los tiempos de los romanos:

"Como entre todos los ejercicios ninguno sea tan necesario para la conservación y defensa de la República como el ejercicio de las armas y el orden militar, por cuya ignorancia - leemos en las historias antiguasla nación española estuvo sometida a romanos y cartagineses, muriendo y perdiéndose siempre con más esforzado ánimo y mayor valentía que sus contrarios por los que eran vencidos, de modo que con el paso del tiempo, viendo que la ventaja que les llevaban los contrarios no se debía a la fuerza ni al ánimo sino a la destreza y el buen orden de milicia, ejercitándose en tal orden y siendo diestros han llegado a ser señores y a dominar a quienes antes los dominaban; y como este ejercicio militar, - con el cual en las guerras pasadas, tan continuas y habituales en esta nuestra Cataluña así contra infieles como contra otras naciones que violentamente buscaron inquietarla, reprimieron y castigaron con honrosas victorias los movimientos de sus enemigos- por la prolongada paz se haya entibiado y haya dejado de oírse hablar de él entre los caballeros jóvenes que de nuevo vienen al mundo, por esta razón los caballeros de Cataluña movidos por el debido celo que conviene a personas que son los nervios y fuerza, valor y defensa del reino, deseando ser diestros para en su caso y lugar servir debidamente a su rey y a su patria, loablemente instituyeron en algunas ciudades de Cataluña cofradías de ejercicios militares y principalmente en la insigne ciudad de Barcelona como cabeza de todo el Principado y defensa del mismo, y como las primeras ordenanzas no pudieron ser tan perfectas...».

La cofradía creada en 1565 y reformada ocho años más tarde se mantiene activa hasta 1640, por lo que nada impide la presencia de don Quijote en los torneos celebrados anualmente, cada año con nuevos alicientes por la concesión de premios al ingenio en la forma de presentarse los aventureros; a la originalidad en el anuncio del ejercicio de las armas

7 En 1533, apenas un niño, Felipe II había asistido a una fiesta semejante organizada en honor de su padre Carlos V por el marqués de Astorga (véase DuRÁN, op. cit., págs. 187-189). 
o en la indumentaria de los personajes que, en algunos casos, recuerdan a quienes combatieron a Tirante el Blanco o a don Quijote; en 1587, la novedad fue un torneo que los «puristas» consideraron «impertinente y desacostumbrado ${ }^{8}$ o impertinente por salirse de los caminos trillados, pero lo suficientemente atractivo para quien, como Cervantes, tiene afán de novedades y hace celebrar en honor de don Quijote un simulacro de combate marítimo-terrestre: «Tendieron don Quijote y Sancho la vista por todas partes; vieron el mar, hasta entonces dellos no visto... Comenzaron a moverse (las galeras) y a hacer modo de escaramuza por las sosegadas aguas, correspondiéndoles casi al mismo modo infinitos caballeros que de la ciudad sobre hermosos caballos y con vistosas libreas salían. Los soldados de las galeras disparaban infinita artillería, a quien respondían los que estaban en las murallas y fuertes de la ciudad... ${ }^{9}$.

La novedad de 1605 consistió en la «intervención» en el torneo de un jinete moro acompañado de dos trompetas vestido de damasco rojo a la morisca. El jinete l!evaba clavado en la punta de la lanza un cartel de desafío en el que se decía que los reyes de Valaquia, Persia, Caramania y de las islas de Tarascantón y del mar Egeo se ofrecían a combatir con cuantos, con fuerte ánimo, noble y altivo aspiraban a conseguir fama en el campo sangriento y áspero del impecable e iracundo Marte, y de manera especial con los caballeros de la ciudad de Barcelona donde con más esfuerzo, rigor y destreza se practicaba la caballería. Los reyes querían que por su condición de reyes e invencibles se les prestara vasallaje y si así no se hacía pedían campo para que en él resplandeciera la verdad, y dejaban al arbitrio de los caballeros de la ciudad la elección de las armas: a caballo con adarga y lanza o a pie con espada y pica ${ }^{10}$.

DURÁN, op. cit., pág. 215.

Pág. 653.

DuRÁn, op. cit., págs. 237-238. Los elogios a Barcelona como lugar donde mejor se rendía culto a las virtudes caballerescas son explicables si tenemos en cuenta que ya en el siglo xv hay en la ciudad academias o escuelas en las que se preparan los futuros caballeros: en 1476, tras haber aprendido el oficio de las armas, Pere Bover aspira a ser nombrado maestro en el arte de manejar la espada, el escudo y la lanza y solicita ser examinado por los maestros Bartomeu Torrent, Jaume Barrera, Joan Trillones y Guillem Masada en presencia de su padrino Jaume Guixós y de cuantos quisieran asistir al examen; lo superó brillantemente, aunque para autorizarie a enseñar se le exigirá, además, prestar ante una señal de la cruz formada por dos espadas el juramento de los caballeros: defender la fe católica, proteger viudas y huérfanos... Como a otros maestros, le fue impuesto el birrete, rojo en este caso, y por tres veces fue proclamado en alta voz «preoste y maestro con facultad de tener discípulos» (DURÁN, op. cit., págs. 207-208). 


\section{CABALLEROS DE SANTIAGO EN ÁVILA}

Arévalo, Madrigal o Ávila no son Barcelona y difícilmente podrán encontrarse en sus archivos ordenanzas tan pormenorizadas como las de Sant Jordi ni mucho menos una relación de los torneos y justas celebradas, de los vencedores, de los premios concedidos..., pero no hay la menor duda de que en la ciudad y villas abulenses las fiestas fueron celebradas con torneos y festejos "militares" que, en Castilla, incluyen casi de manera obligatoria las corridas de toros por los caballeros, organizados en cofradías puestas bajo la advocación del apóstol Santiago, patrón de Castilla como San Jorge lo es de Aragón, y realzado por la existencia de una Orden Militar que lleva el nombre del apóstol, aunque quizá sería más correcto decir que lleva el nombre de la sede arzobispal de Compostela: en sus orígenes, la Orden recibe el nombre de Cáceres, la ciudad en la que fue creada, y su vinculación a Extremadura llevó al arzobispo de Compostela a convertir a los caballeros de Cáceres en caballeros o canónigos de Santiago para que, con el nuevo nombre, dieran preferencia a la ocupación de Mérida, cuya sede arzobispal había sido trasladada a Compostela en tiempos del obispo Gelmírez: si Mérida es ocupada por enemigos de Compostela, será restaurada la sede y con ella desaparecerá el arzobispado compostelano. Los caballeros hicieron honor a su nombre, ocuparon Mérida, y Santiago de Compostela es todavía hoy ciudad arzobispal.

Ávila se vio envuelta directa e indirectamente en el acuerdo entre la Orden de Cáceres y el arzobispo compostelano y no estará de más recordar su contribución al mantenimiento de la archidiócesis compostelana. Cuando el arzobispo ofreció al maestre de la Orden hacerlo canónigo de la iglesia y se avino él a ser caballero de la nueva milicia, ofreció a los santiaguistas la mitad de los votos ofrecidos al Apóstol en Salamanca, Zamora y Ciudad Rodrigo y la totalidad de los votos de la diócesis de Ávila. Por este tiempo, algunos caballeros de Ávila - que ya habían demostrado su valor militar combatiendo a los musulmanes- ${ }^{11}$ crean una nueva cofradía $u$ orden militar semejante a la de Cáceres-Santiago, se

1 Baste recordar la Crónica de la Población de Ávila, las páginas dedicadas a la repoblación y defensa del territorio por Baffios, A., Estructuras agrarias y de poder en Castilla. El ejemplo de Ávila (1085-1320), 1. Salamanca-Ávila 1983, págs. 128 y ss. o las líneas que a los caballeros abulenses y a los elogios que se les dispensan las fuentes musulmanas dedica SÁNCHEz Albornoz, "Siempre en Ávila», en Ávila. El Alma andariega. Madrid 1981: «Han venido a exaltarlas con sus elogios los propios enemigos, los musulmanes, contra quienes los caballeros de Ávila emplearon la fuerza de su brazo. Ya al-Idrisí se había hecho lenguas de las grandes condiciones de jinetes de los abulenses. El historiador almohade Sahib al-Sala hizo más... Abu 
unen a ésta en mayo de 1172 aunque conservando su independencia ${ }^{12}$, y fijan los límites militares de la Orden: expulsar a los musulmanes de España, combatirlos en Marruecos si necesse fuerit in Iherusalem.

Las relaciones de Ávila con Santiago y con el mundo caballeresco continúan después de 1172 y aunque no puede prestarse fe al relato del padre Luis Ariz sobre el armar caballeros abulenses por parte del conde don Ramón de Borgoña ${ }^{13}$, su versión responde a la práctica habitual en los siglos xIV y posteriores y tal vez todavía en 1603 en el momento de terminar su obra ${ }^{14}$ :

«el señor conde mandó a Millán de Llanes, que viajase con las armaduras... al Templo del señor Santiago ${ }^{15}$, e las colgase ante su altar, para que en essa noche fuessen veladas por los donzeles, y armados Caballeros el siguiente día... E el señor obispo les fabló en esta guisa: Donzeles nobles, que oy avedes de ser armados cavalleros, atended qué fazienda sea la Cavallería, ca Cavallería dizen nobleza, e el home noble non á de fazer tuerto, nin vileça, por cosa alguna... De la Cavallería, y exercicio de las armas, pende el sossiego, paz, justicia, y salud, en la República bien concertada, y con ella está preservada de todos los daños que le pueden venir de sus enemigos...»,

frases que habrían suscrito gustosos Felipe II y Alfonso Quijano ${ }^{16}$.

Yaqub, el segundo califa de la dinastía, da noticias a sus súbditos africanos de la victoria de su ejército sobre las tropas de Ávila, y, al hacerlo, dice que eran los más valerosos guerreros con los que los almohades habían tenido que luchar hasta allí (págs. 77- 78).

12 Puede verse el texto completo en el apéndice; por lo que se refiere a la independencia reclamada por los abulenses, baste recordar que condicionan su ingreso en la Orden de Santiago a que se les permita conservar los bienes que poseen y puedan conseguir en el futuro, fijan la distribución del botín que consigan en tierras musulmanas, y disponen que el preceptor que ellos se den sea confirmado sin discusión por el maestre de Santiago.

13 Historia de las grandezas de la Ciudad de Ávila. Alcalá de Henares 1607 (reed. Ávila 1978), págs. 132 y ss.

${ }_{14}$ El resurgir y la organización de la caballería en el siglo XIV por iniciativa de Alfonso XI han sido estudiados, entre otros, por García, I., La Orden de la Banda, "Archivum Historicum Societatis lesu», LX, 1991, págs. 29-89.

${ }_{15}$ De esta iglesia de Santiago se conservan las «Ordenanzas para el cura y beneficiados de la parroquia», de 1498, editadas por SoBRINO, T., Documentos de antiguos Cabildos, Cofradías y Hermandades abulenses. Ávila 1988, págs. 157-163; en ellas no se alude para nada a los caballeros.

${ }_{16}$ Cabría hablar de las contrapartidas de este servicio de armas, contrapartidas que se encuentran fijadas por Alfonso $X$ en las Partidas para los caballeros del reino, y para los de Ávila en 1256 en documento que confirman los monarcas posteriores: «los cavalleros que tovieren las mayores casas pobladas... e tovieren cavallos e armas, et el cavallo de treynta maravedís arriba, e escudo e lança e loriga e brafoneras e perpunt e capiello de fierro e espada, que non pechen... e que escusen sus paniaguados e sus pastores e sus colmeneros e sus amos que criaren sus fijos e ortolanos e sus molineros e sus yugueros e sus medieros e sus mayordomos que ovieren en esta guisa..." (Ed. el documento LUIS, C. y SER, G., Documentación medieval del Asocio de la Extinguida Universidady Tierra de Ávila, I. Ávila 1990, págs. 47 y ss.) 
Si no conocemos textos fidedignos sobre armar caballeros en Ávila - sin responsabilidad para los abulenses-- le cupo el dudoso honor de ratificar la deposición como maestre de Santiago del Infante Enrique de Aragón, y de proceder al destronamiento de Enrique IV en actos que recuerdan punto por punto el ceremonial para destituir a los caballeros indignos del orden recibido. Las Partidas establecen que se pierde el honor y orden de la caballería cuando estando «de servicio» el caballero vende el caballo o las armas o las pierde a los dados o las da a malas mujeres o las empeña en la taberna, cuando roba o hace robar las armas de sus compañeros, arma caballero a quien no lo merece, ejerce oficio manual "por ganar dineros», huye de la batalla, desampara a su señor...; en todos los casos se le priva de la caballería del modo siguiente: «deve mandar el Rey a un escudero que le calçe las espuelas e le çinga el espada e que le corte con un cuchillo la cinta de la parte de las espaldas e otrosí que taje las correas de las espuelas teniéndolas calçadas..." ${ }^{17}$.

La sequedad del texto legal, que sirve de modelo todavía hoy a la degradación de los militares, adquiere gran expresividad en la versión que de este mismo hecho ofrece Tirante el Blanco al hablar de la Orden de la Jarretera: el caballero que por oro o plata actúa contra el orden de caballería merece ser denunciado al rey, llevado ante él armado de todas sus armas, subido en un catafalco para que todos puedan verle mientras trece presbíteros rezan el oficio de difuntos como si «lo tuvieran allí muerto", y a cada salmo van despojándole de sus armas, primero el bacinete porque ha consentido con los ojos actuar contra su orden, después la manopla de la mano derecha con la que tomó el oro por el que defraudó a la caballería, más tarde la manopla izquierda... hasta despojarle de todas las armas ofensivas y defensivas que serán tiradas al suelo mientras reyes de armas, heraldos y portavoces - por este orden- dicen en voz alta: "Este es el capacete de aquel desleal defraudador de la bienaventurada orden de caballería...» En el lugar habrá agua caliente en una bacía de oro o plata y tras despojarle de cada arma, preguntarán los heraldos: «¿Cómo se llama este caballero", dirán su nombre los portavoces y replicarán los reyes de armas: «No es verdad, mejor es aquel mal caballero villano que en poco ha estimado la orden de caballería» y añaden los sacerdotes: «Pongámosle nombre...", le echan agua caliente en la cara al tiempo que dicen: "Tú serás nombrado de ahora en adelante por tu derecho, con el nombre de traidor». El rey se viste de luto con doce de sus caballeros y dan muestras de gran tristeza hasta que el caballero,

17 Partida 2." , título 21, Ley XXV. Utilizó la versión glosada por el Licenciado Gregorio López en 1555 , reeditada en 1985 . 
desarmado, desciende del catafalco no por la escalera que utilizó para subir sino que «lo atan con una soga y tíranlo al suelo», lo llevan a la iglesia de San Jorge donde, echado en el suelo, le rezan el salmo de maldición y dictan sentencia contra él, "de muerte o de cárcel perpetua» ${ }^{18}$.

El castigo del mal caballero no es un invento del novelista valenciano aunque pueda parecer que éste dramatiza el acto; tenemos copias casi literales de actos semejantes en la llamada Farsa de Ávila y en la menos conocida pero no menos interesante Farsa de Uclés refrendada por orden de Juan II en la ciudad de Ávila.

Los conquenses Pedro Carrillo de Huete y el obispo Lope Barrientos nos informan con detalle del maestrazgo de la Orden de Santiago ejercido por Álvaro de Luna antes de 1445 y de la singular ceremonia en la que fue depuesto el maestre legítimo, el infante Enrique de Aragón. En sus enfrentamientos con Juan II, Enrique llega a combatir al monarca desde el castillo de Alburquerque y el monarca «acordó con los prelados y cavalleros que allí con él estavan que pues el ynfante... se avía rrevelado... que le devían privar del maestradgo de Santiago... Y por acuerdo de todos ellos, fue dado al condestable don Alvaro de Luna la administraçión del dicho maestradgo de Santiago, en tanto que se proveya de maestre...» ${ }^{19}$.

De la misma forma que el rey no olvida la legalidad al nombrar maestres e intenta convencer o comprar los votos de los electores, también la deposición ha de ser legalizada y Juan II ordena que se reúna el Capítulo en Uclés con el prior y subprior del lugar "donde es uso y costumbre de elegir maestre, y asy mismo de lo disponer», manda hacer una estatua y colocarla en la silla maestral vestida con los atributos del cargo: «una capa blanca y un birrete en la cabeça, y un estoque çeñido, y el sello de maestre colgado de la mano, y el pendón maestral colgado de aquella mesma mano" y puesto que, a juicio del monarca y de sus fieles, el infante había incumplido los estatutos de la Orden de Santiago se procede a privarle del cargo y prohibirle que utilice el título de maestre.

"Y mandado esto, fueron a la silla donde estava asentada aquella estatua. E luego el comendador mayor de León quitóle el estoque que tenía ceñido, y el comendador Vidao de Soto quitóle el sello que tenía colgado de la mano, y el comendador Juan Ruiz de Colmenares quitóle el pendón, y el comendador García de Cardenas quitóle el birrete de la

18 Sigo la versión castellana realizada por F. F. Vidal para Alianza Editorial, Madrid 1969. El texto se encuentra en el vol. 1, págs. 118-119.

19 Carriazo, Juan de Mata, Refundición de la Crónica del Halconero por el obispo Don Lope Barrientos. Madrid 1946, pág. 85 y ss. 
cabeça, y el comendador Juan Martínez de Prado quitóle la capa, y el comendador don Fernando de Portugal quitóle la estatua de la silla» ${ }^{20}$.

La deposición fue ratificada en Ávila en la elección de Álvaro de Luna, según recuerda su Crónica:

«El Rey escribió sus cartas para los treze cavalleros de la Orden de Santiago, que han poder elegir maestre, e para los priores e otros caballeros e freyles de la Orden que a la tal eleccçion han costumbre de se allegar. Mandándoles por aquéllas, que luego se juntassen e se viniessen a... la çibdad de Ávila... porque allí fiziesen la eleccçion del maestrazgo en el Condestable don Álvaro de Luna, por ser él tan bueno caballero e tan cuerdo, e que tan bien sabría sostener e acreçentar la Orden... E todos alegremente e en una concordia se ayuntaron en la iglesia mayor de Ávila e... eligieron al Condestable por su maestre...» ${ }^{21}$.

A la deposición en efigie del infante Enrique replica éste tomando por asalto la casa del condestable de Toledo y mandando destruir un busto que Álvaro de Luna había encargado para poner en su tumba, acción que mereció una respuesta burlona en la que el condestable, en verso, recordaba al infante que su efigie nada había tenido que ver en la derrota sufrida por los infantes de Aragón en aguas de Ponza:
Si flota os combatió
en verdad Señor Infante
mi vulto no vos prendió
quando fuiste mareante porque hiçiésedes nada a una semblante figura que estava en mi sepultura para mi fin ordenada ${ }^{22}$.

Veinte años más tarde, los abulenses serán testigos directos de la deposición de Enrique IV: en un llano cerca de las murallas de Ávila se elevó un cadalso y en él una silla con una estatua que representaba a Enrique «con corona en la cabeza e cetro real en la mano». Ante la estatua se leyeron acusaciones y agravios que justificaban la deposición y leídas estas cosas el arzobispo de Toledo le quitó la corona de la cabeza, el marqués de Villena le arrebató el cetro, el conde de Plasencia le despojó

20 Refundición, págs. 111- 112.

21 Crónica de don Alvaro de Luna condestable de Castilla, maestre de Santiago (ed. de Juan de Mata Carriazo). Madrid 1940, págs. 180-182.

22 Op. cit., Il, pág. 369. 
de la espada y otros nobles retiraron «todos los otros ornamentos reales» y a patadas tiraron la estatua al suelo diciendo: «a tierra, puto», mientras allí los presentes gemian y lloraban como si estuvieran en un funeral por el rey, según nos han transmitido Diego de Valera, Alonso de Palencia y Diego Enríquez del Castillo ${ }^{23}$.

\section{COFRADIAS DE CABALLEROS ABULENSES}

La pervivencia del espíritu caballeresco en las ciudades y villas castellanas explica la favorable acogida que dieron poblaciones como Arévalo, Ávila y Madrigal a la real cédula de 1572, a cuyo contenido hemos hecho diversas alusiones en las páginas anteriores y detallamos a continuación.

El escrito está perfectamente estructurado: algunas personas han llamado la atención del rey sobre el gran número de caballeros existentes en el reino que no están preparados para ejercer su oficio y defender el territorio, y han hecho ver que un posible remedio a esta falta de preparación sería la creación en cada ciudad y villa de alguna cofradía, compañía $u$ orden de caballeros y personas de calidad que se encargase de organizar cada año justas, torneos, juegos de cañas y otros ejercicios militares que serían pagados por los municipios bajo la coordinación y supervisión del corregidor de cada lugar que informaría al monarca de cuanto se acordase. Considerando útil el consejo, Felipe II se dirige a los concejos y les ordena que, tras las oportunas reuniones de los cabildos a las que podrán y deberán ser invitados los caballeros, se hable de la propuesta de crear la citada cofradía, de sus posibles ordenanzas, del nombre del santo patrono, del apoyo que podría prestar el monarca, de la ayuda que cada villa o ciudad está dispuesta a ofrecer y de las fiestas que se piensan hacer para lograr que los caballeros y nobles estén perfectamente preparados para la guerra. Los nobles y clérigos recibieron una carta en la que se les pedía enviaran una relación de las fortalezas, pertrechos de guerra y hombres a su cargo y estuvieran preparados para cualquier emergencia.

${ }^{23}$ Los textos de Valera y de Enríquez del Castillo están publicados en Crónica de los Reyes de Castilla, III. Madrid 1953, págs. 33 y 144-145 respectivamente; el relato de Alonso de Palencia puede verse en su Crónica de Enrique $N$. Valladolid 1973, I, págs. 167-168. He recogido los textos en mi artículo «El rey ha muerto. ¿Viva el Rey!", Hispania 177, 1991, págs. 27-32.

En las páginas 26-27 del citado artículo reproduzco el texto de los /lantos y alegrias hechos en Arévalo al conocerse la muerte de Juan II y ser proclamado rey Enrique IV; sigo la versión publicada por MonTalvo, Juan José, De la historia de Arévalo y sus sexmos. Ávila 1983, págs. 222-223. 
El Archivo de Simancas conserva para Madrigal la respuesta del concejo a la real cédula: según los regidores, no tiene sentido crear una cofradía de caballeros e hidalgos cuando la mayoría de los que habitan en la villa pertenecen a la cofradía de Santiago y celebran la fiesta del santo patrono recorriendo Madrigal a caballo, práctica que ha disminuido considerablemente desde que Felipe II prohibió celebrar corridas de toros.

Si el monarca quiere que los caballeros estén preparados, nada mejor que mandar se celebren corridas de nuevo y "el exerçiçio de la dicha cavallería se continuaría más y se entiende yría en abmento y no en disminuçión» siempre que, además, el rey ofrezca algunas ventajas o preeminencias para la adquisición de caballo y armas. La villa, por su parte, está dispuesta a colaborar en los gastos que se produzcan (música, lanzas, tela y libreas) en la celebración de justas, torneos, juegos de cañas, correr la sortija..., pero necesita la autorización del monarca para crear algún impuesto extraordinario pues los bienes de propios de Madrigal son insuficientes para atender los gastos.

El texto arevalense es bastante más amplio e incluye copia de la real cédula que es leída públicamente en el consistorio y cumplida en todos sus puntos. La carta, fechada el 6 de septiembre, es leída el día 11 y sometida a un primer análisis tras el que se decide reunirse de nuevo el miércoles tras llamar a los caballeros de la villa para juntos «tratar lo que convenga al serviçio de su magestad". La nueva reunión se pospuso hasta el 15 de noviembre, quizá por la dificultad de reunir a regidores y caballeros, y a ella asistieron el corregidor, licenciado Barrientos, los regidores Diego de la Cárcel, Francisco de Tapia, Hernando Altamirano, Juan y Alonso Dávila y don Rodrigo Ronquillo y los caballeros Francisco de la Cárcel, Bartolomé Muñoz, Rodrigo de Ungría, Lope del Río, Toribio de Badillo, Diego Meléndez, Francisco Osorio, Álvaro de Ungría, Juan Vázquez de la Quadra, Gonzalo de la Cárcel, Pedro del Río, Luis de Cardenal, Juan Callejo y Luis de Montalvo, así como el escribano del concejo Francisco López. El acuerdo a que se llegó fue crear una comisión reducida que integrarían los regidores Alonso de Ávila y Rodrigo Ronquillo y los caballeros Francisco de la Cárcel y Toribio de Badillo que junto con el corregidor estudiarían la cédula real y propondrían una respuesta.

La nueva reunión del consistorio tuvo lugar el 18 de noviembre con asistencia de algunos de los caballeros antes mencionados $y$, de común acuerdo, dieron una respuesta que en poco difiere de la facilitada por el concejo de Madrigal: que el rey solicite al papa licencia para correr toros en la villa y se faciliten los medios para que haya ministriles, trompetas, timbales..., pues, como indicarán prácticamente todos los concejos, los bienes de propios son insuficientes para atender a estos gastos. Arévalo 
no se limita a pedir sino que sugiere una fórmula de cubrir los gastos: en las derramas extraordinarias motivadas por la celebración de nacimientos de miembros de la familia real, construcción de puentes o fuentes, salarios de médicos cirujanos o preceptores de Gramática, la Tierra contribuye con cuatro partes y una paga la Villa; si el rey permite que esta quinta parte se pague con cargo a otra partida, "con penas de cámara», la villa dedicará su parte a los gastos de las fiestas caballerescas y así podrá hacerse «cada año una cofradía de gente noble a la adbocaçión del apóstol Santiago y se haría cada un año el dicho día juegos de cañas y abría una justa e torneos una vez en el dicho año por donde ubiese cunplido e fecho lo que vuestra magestad manda».

El corregidor de la villa transmite el acuerdo del concejo el día 20 de noviembre no sin recordar su importante papel para que se reunieran regidores y caballeros; de su escrito parece deducirse que el retraso en contestar se debió al interés de Arévalo por no desentonar, por ofrecer respuesta semejante a la que ofrecerían las villas y ciudades próximas: «como personas de no mucha espiriençia y celosos de servir a V. Magestad quisieron ver lo que los lugares comarcanos respondían...».

Cinco días tarda en llegar la carta del rey a Arévalo y catorce a Olmedo ${ }^{24}$ desde donde responde el obispo Álvaro de Mendoza que lamenta la falta de armas, caballos y gente experimentada, carencia que hace inútil cualquier esfuerzo pues aunque hubiera dinero en abundancia mal podría poner en condiciones de defensa las fortalezas mientras no dispusiera de hombres aptos para estas tareas. Por lo que se refiere a la relación de fortalezas que pide el monarca, Álvaro recuerda que el obispado sólo posee la de Bonilla en cuya reparación ha gastado grandes cantidades por lo que sería preciso, para mantenerla en condiciones de defensa, que colaborasen los súdbitos de la zona a los que presenta «más relevados de las cargas que otros", es decir, menos cargados de impuestos.

El concejo de Ávila se reúne el 13 de septiembre para dar lectura a la carta real, que se copia, y nombrar una comisión de caballeros-regidores y caballeros-particulares para que discutan los pormenores y ofrezcan la respuesta que consideren pertinente en el plazo de tres días, plazo que fue suficiente para ofrecer una memoria o "parecer" del que se desprende, como no podía ser menos, que la falta de toros se ha traducido en una disminución del número de caballos y ésta en un descenso de las fiestas, de los juegos y, en consecuencia, de la práctica militar de los

\footnotetext{
24 La carta del corregidor de Arévalo salió de la villa el día 20 de noviembre y fue entregada
} en la corte el día 23; la del obispo de Ávila tardó once días para ir de Olmedo a Madrid. 
caballeros. El informe contiene, además, otros seis pareceres de los que el segundo señala la obligación del concejo de tener instrumentos musicales y todo lo necesario para justar así como arneses para que puedan participar en los juegos los hidalgos que no dispongan de medios.

Entre los acuerdos se incluye la re-creación de una cofradía dedicada al apóstol Santiago, en cuya fiesta se harían juegos de cañas; sus estatutos serían los que decidiera una comisión nombrada al efecto partiendo siempre de las ordenanzas que tenía la cofradía que existió «quando avíe y se corrían los toros", y el número de cofrades deberá ser de cuarenta para que, aunque haya algunos impedidos, puedan celebrarse las fiestas dignamente.

El informe de los caballeros fue considerado y tenido en cuenta por los regidores que lo hacen suyo y le dan forma «literaria» el día dieciocho para enviarlo al monarca: para que no haya duda se insiste de nuevo en que el día de Santiago haya juegos de cañas y otros «porque no aviéndolos no puede aver hexerçiçio de cavallos ni regoçijo ni se animarían los cavalleros a tenerlos ni hacer fiestas»; el campo de entrenamiento ha de estar preparado todo el año y la ciudad pondrá a disposición de quienes no las tengan las armas necesarias pues de otra manera no podrá haber justas por ser pocos los hidalgos que disponen de arneses propios y muchos los que no poseen los «aparejos» necesarios. También correrá de cuenta de la ciudad la música, el salario de un armero que tenga en condiciones las armas, y los gastos que se produzcan el primer año; más adclante se verá qué conviene hacer para conseguir que participen y se entrenen los numerosos caballeros de la ciudad que están dispuestos pero no tienen los posibles requeridos ni puede facilitárselos Ávila que carece de medios para atender las necesidades ordinarias y no puede ni soñar en atender éstas que le vienen de nuevo, para las que solicita del monarca autorización para crear una renta perpetua de doscientos ducados anuales y, una vez más, que «se puedan correr toros»: si hay toros y rentas, el monarca podrá contar con los abulenses porque sus nobles están siempre dispuestos a servir al rey si se les facilitan los medios y, repitámoslo una vez más, si hay toros, petición que hemos visto se hace en Madrigal y en Arévalo y harán por los mismos días numerosos concejos castellanos entre los que merece atención especial el de Ciudad Rodrigo, que ha mantenido la tradición taurina hasta la actualidad.

El concejo mirobrigense recuerda con nostalgia la existencia de una cofradía puesta bajo la advocación de San Juan Bautista en cuya fiesta los caballeros y nobles recorrían la ciudad a caballo y alanceaban los toros que les facilitaba la ciudad que, tras la corrida ofrecía un almuerzo a los caballeros. Además de esta cofradía, cuya fiesta era el 24 de junio, 
hubo otra dedicada a Santiago en cuya vigilia se reunían los hermanos para oír vísperas y después cabalgar por la plaza y por toda la ciudad; el día siguiente oían misa, alanceaban toros y jugaban cañas vestidos con las libreas e insignias del santo... hasta que por no haber toros las fiestas se han «resfriado».

Entusiastas, entonces y ahora, de los toros, los mirobrigenses ofrecen al monarca una solución milagrosa para movilizar a los súbditos en defensa del reino: si se corren toros en todas partes, la gente se animará a tener caballos y los mozos se harán buenos caballeros, cosa que no ocurre cuando ellos escriben a Felipe II, al que piden, para que haya caballos en abundancia, que prohiba echar las yeguas a los asnos y que ordene en la ciudad la preparación de dehesas para yeguas, potros y caballos, para verano e invierno. Las cofradías tendrán vida si hay fiestas a caballo y dos al año parecen pocas por lo que se propone que en las ordenanzas que se redacten se incluya la obligación de una nueva fiesta el día de Nuestra Señora de Agosto y otras tres entre este día y los Carnavales.

Los caballeros están dispuestos a prepararse para la guerra pero no a su costa y piden que la ciudad corra con los gastos de tela, trompetas, lanzas, atabales, tambores, timbales, pífanos..., así como con el salario de armeros, ballesteros, silleros, lanceros y de un maestro esgrimidor cuyos servicios son, sin duda, tan necesarios como los del maestro de montar a la brida pues en la ciudad sólo se sabe montar a la jineta y «para la brida ay falta de cavalgadores». El coste total de la operación exige una renta anual de trescientos mil maravedís que los caballeros proponen se sitúen en los baldíos y comunes de la Ciudad y de la Tierra.

Por otra parte, si los caballeros han de servir, justo es que reciban adecuada compensación que no es sino el mantenimiento de algunos privilegios como el de ir armados o el de no ver embargados por deudas el caballo, las armas, la cama o un esclavo; y para que nadie pueda acusarlos de egoísmo piden que se respeten los privilegios de la Ciudad, uno de los cuales es a su vez un privilegio de los caballeros, exentos de contribuir en los repartimientos en los que sólo pagan los pecheros.

Conocedores de su tendencia al gasto excesivo y de la ruina que comporta su exhibicionismo, los caballeros mirobrigenses recuerdan que la dedicación a las armas ha descendido a medida que aumentaba el gusto por los "trajes y atabíos" y solicitan una ley que prohiba llevar sobre la ropa más de una faja o ribete por guarnición, forrar con seda trajes de seda o gastar más de un ducado en la hechura de cualquier traje; si así 
se hace, el ahorro realizado permitirá a los vasallos del reino «tener armas y cavallos y estar exerçitados" para servir al rey cuando sea necesario ${ }^{25}$.

\section{APÉNDICE DOCUMENTAL}

Arévalo, 11 de septiembre de 1572 .

Los regidores y caballeros de la villa de Arévalo piden al rey autorización para pagar con cargo a las penas de cámara los gastos que originaría una cofradía de caballeros situada bajo la advocación del apóstol Santiago. Si asi se autorizase todos los años habría juegos de cañas, justas y torneos.

Diversos de Castilla, leg. 25, fol. 1. El cuaderno está sin numerar; en la numeración dada por mí a las fotocopias, las páginas de Arévalo van de la 55 a la 67.

En la muy noble villa de Arévalo, honze días del mes de setienbre, año del señor de mill e quinientos y setenta y dos años.

Estando en consistorio los illustres señores Justiçia e rregidores, conbiene a saver el señor liçençiado Barrientos, corregidor en la dicha Villa y su Tierra por su Magestad, e Diego de la Cárzel e Juan de Arévalo y Montalvo, e Juan de Avila e Françisco de Tapia e Pero Gómez de Varrionuevo e Miguel de Bazán de Montalvo e Pero Briçeño de la Vega, regidores en la dicha villa, en presençia de mí Françisco López, escrivano del número y del dicho ayuntamiento por su magestad, estando ansí juntos e congregados como lo tienen de uso e de costunbtre para proveher en las cosas tocantes al serviçio de Dios y de su Magestad e bien de la República, ordenaron y mandaron lo siguiente:

Este día, estando en el dicho constorio y ayuntamiento se abrió una çedula y carta de su Magestad, e abierta se leyó, que es del thenor siguiente:

El Rey.

Conçejo, justiçia y regidores, caballeros y escuderos, ofiçiales y onbres buenos de la villa de Arévalo.

25 Reproducimos, en parte, la contestación de los mirobrigenses que resume y concreta las peticiones de la mayoría de las ciudades y villas del reino (véase el apéndice 7). 
Sabed que algunas personas zelosas de nuestro serviçio y del bien público nos an hecho relaçion e representado que, como savíamos, en estos nuestros reynos quanto en otros algunos de la Cristiandad avía gran nobleza y número de cavalleros cuyo propio ofiçio, ministerio y ocupaçion, cunpliendo con la obligaçion de su estado y con lo que ansimismo deven, hera el uso y exerçiçio de las armas y el estar muy puestos y aparexados para las ocasiones de nuestro serviçio y de la causa pública; y que ansí en los tienpos antiguos acostunbraron a estar muy en orden de cavalleros y armas y muy usados y exerzitados en los actos militares; y que, agora, parte con la paz y oçio de tantos años que ha causado en esto de las harmas descuido, parte por ocupaçiones e ynpedimentos, mucha parte de la dicha nobleça y caballeros estavan desarmados y sin caballos y con mui poco uso y exerçiçio de las armas y actos militares, lo cual yba de cada día en tanta disminuçion y quiebra que con ser éste el estado de que tan prinçipalmente dependía la fuerça de nuestro serviçio y la seguridad y defensa de los reinos, como quiera que los ánimos suyos estarían siempre muy prontos y dispuestos para nós servir, se hallarian con tan poco aparexo y dispusiçion y tan enpididos que lo pudiesen mal hazer.

E con esto ansimismo se nos representó que, como hera çierto, en ninguna cosa podíamos hazer mayor merçed y más bien e benefiçio al dicho estado de la nobleza que con mandar mirar e tratar la orden y medios que para el remedio de lo susodicho se pudiesen tener y usar, advirtiendo y propuniendo que entre otros medios en particular sería muy conviniente que en las çivdades, villas y lugares destos reynos los caballeros y onbres prinçipales y de calidad fundasen e ynstituyesen entre sí alguna cofradía, conpañía o horden debaxo de la advocaçión de algún santo con tales hordenanzas, condiçiones y capítulos que por ellos entre otras cosas se ordenasen fiestas en algunos días señalados de justas, torneos e juegos de cañas y otros exerçiçios militares, y que en los mismos lugares ansimismo de público se ordenassen las dichas fiestas e regoçixos ayudando con lo que se pudiese y fuese justo para las dichas fiestas, e que los nuestros corregidores y justiçias y caballeros prinçipales tomasen cargo de lo mover, procurar y poner en horden, e que de todo se nos enviase relaçión ansí de presente como para adelante en cada un año, e que dando nós a esto la utilidad y favor que entendían daríamos e queriendo thener dello particular notiçia e relaçión sería muy grande y prinçipal parte para que los dichos se hexerçitasen, pusiesen y estuviesen armados, encavalgados e prevenidos.

E aviéndonos paresçido el dicho recuerdo y lo que ansí se nos á representado digno de consideraçión, es por lo que nós deseamos e abemos de procurar que la nobleza y caballeros de nuestros reyros sean ynstituidos e criados en la virtud, costunbre, uso y exerçiçio de las armas e actos militares conforme a lo que su estado, profesión e sangre les obliga por lo que toca a su onor e auturidad, e por el amor grande que nós les tenemos, avemos acordado de que por todas las vías e medios que se pudiese se provea y dé orden en esto, e avemos determinado de tener dello gran cuenta y cuidado e para proveher en ello con más fundamento y entender mexor los medios de que se podría usar e lo que se podría probeher y ordenar, os mandamos que luego que esta nuestra çédula hubiéredes resçevido, juntándoos en vuestro cavildo e ayuntamiento, llamando para ello ansí a los presentes como a los ausentes que estuvieren en parte que con brevedad puedan benir e llamando ansimismo, demás de los regidores e personas del cavildo, algunos otros cavalleros çelosos de nuestro serviçio y del bien e benefiçio público e del onor e auturidad de su estado, y ansi juntos trateys, platiqueis y confirais 
sobre todo lo susodicho y espeçialmente en lo que toca a la ynstituiçion de la dicha cofradría, conpañía o orden o de la forma e manera que ésta se podría ynstituyr y hazer e con qué ordenanzas, capítulos y condiçiones y devaxo de qué título e nonbre e qué aparejo y dispusiçión ay en esa villa para ello y qué favor, auturidad y calor convendría que nós demos y en qué de nuestra parte les podremos hazer merçed y asistençia y qué fiestas y exerçiçios se podrían ynstituir y ordenar y con qué se les podría de público y de los propios ayudar; y si demás del remedio de la dicha ynstituiçión y cofradía y fiestas abrá otros endereçados al dicho fin de que los caballeros e nobleza estén armados, encabalgados, usados y exerçitados.

Y abiendo sobre todo platicado nos enviareis relaçion muy particular de lo que resulta y parece porque lo queremos entender muy de fundamento e tener dello particular cuenta para lo probeher y ordenar como convenga.

Fecha en Madrid a seis de setiembre de mill y quinientos e setenta y dos años.

Yo el Rey. Por mandado de su magestad, Juan Vázquez.

E ansí leyda por mí el dicho escrivano la dicha çédula que de suso va yncorporada, los dichos señores Justiçia e regidores trataron y confirieron sobrello e se acordó que el miércoles se junten y se llamen cavalleros que a ello conbengan e juntos se tratará lo que convenga al serviçio de su magestad.

En la villa de Arévalo e quince días del mes de nobienbre, año del señor de mill y quinientos y setenta y dos años, estando en consistorio los ylustres señores Justiçia e regidores de la dicha villa, conviene a saver el señor liçençiado Barrientos, corregidor e Diego de la Cárcel y Françisco de Tapia y Hernando Altamirano e Juan de Ávila e Alonso de Ávila e don Rodrigo Ronquillo, regidores de la dicha villa, en presençia de mí Françisco López, escrivano del dicho ayuntamiento por su magestad, dixeron que se á mandado llamar para este ayuntamiento a muchos caváleros de esta villa para conferir e tratar, como otras veçes los dichos señores Justiçia e regidores lo an tratado e conferido, lo que su magestad quiere e manda por su çédula etc. $Y$ estando juntos y abiendo tratado y platicado sobre lo suso dicho, e aviéndoles sido leida la çédula real de su magestad y estando juntos con los dichos señores Justiçia e regidores don Françisco de la Cárçel, Bartolomé Muñoz, Rodrigo de Ungría, Lope de Rio, Toribio de Badillo, Diego Meléndez, Françisco Osorio, Álvaro de Ungría, Juan Vázquez de la Quadra, Gonçalo de la Cárçel, Pedro del Río, Luis de Cardenal, Juan Callexo, Luis de Montalvo, caballeros vezinos de la dicha villa, todos juntos los susodichos e para este dicho efecto se nonbraron del ayuntamiento a los señores Alonso de Ávila e don Rodrigo Ronquillo e de los cavalleros al señor don Françisco de la Cárçel e Toribio de Badillo, los quales azetaron, para juntarse con el señor corregidor y dar la orden para escrevir esta nuestra en respuesta de la zédula real a su magestad. $Y$ ansí se acordó y lo firmaron de sus nombres el dicho señor corregidor y regidor más antiguo y los demás 10 rubricaron de sus rúbricas. El Liçençiado Barrientos. Diego la Cárcel. Pasó ante mí Françisco López.

En la villa de Arévalo a diez y ocho días del mes de nobienbre, año del señor de mill y quinientos e setenta y dos años. Estando en consistorio los illustres señores Justiçia e regidores de la dicha villa por su magestad, conviene a saver: el señor liçençiado Barrientos e Diego de la Cárçel e Juan de Arévalo e Juan Dávila e Hernando Altamirano y don Rodrigo Ronquillo e Alonso Dávila y Montalvo e Pero 
Briçeño de la Vega regidores y en presençia de mí Françisco López, escrivano del dicho ayuntamiento por su magestad, hordenaron e mandaron lo siguiente:

Este día se juntaron en el dicho consistorio los cavalleros que para ello fueron llamados que son don Luis de Badillo e Pero de Río e don Françisco de la Cárçel e Lope de Rio e Luis de Cardenal y Bartolomé Muñoz e se conformaron los señores Justiçia e rregidores e rrespondieron lo que se sigue:

\section{R. Magestad.}

Vista una çédula de vuestra magestad fecha a seis de setienbre, refrendada de Juan Vázquez por la qual mandades a la dicha villa, regidores, cavalleros della platiquen e confieran qué horden se podría tener para que en esta villa se hexerzitasen la gente noble ansí haziendo juegos de cañas como haziendo justas e torneos, si para esto conbendría hazer ynstituiçión de alguna cofradría e adbocaçión de algún santo, dizen que suplicando vuestra magestad a su santidad dé liçençia para que se corran toros e mandando que en esta villa aya menistriles e tronpetas e atavales e torneos e lançero e aya tela, e mandando vuestra magestad que en esta villa ubiese tela e arneses para todo lo qual esta villa no tiene posibilidad a causa de tener propios tan tenues que para qualquier edifiçio que quiere hazer se pide liçencia a vuestra magestad para que se hechen los dichos gastos en sisa cuya causa esta villa tiene carta executoria con que la Tierra della quando vuestra magestad manda se agan algunos gastos ansí de regozixos e nasçimientos de reyes proxenitores de vuestra magestad, como para qualquier contribuçion de gastos, de fuente o puente, salarios de médicos zuruxanos, preçeptores de Gramática, las aldeas de la Tierra desta dicha villa de çinco partes contribuyen con quatro partes e la quinta parte solamente la Villa e haziendo vuestra magestad merçed por la orden executoria la quinta parte que viniese a pagar la villa sería gran vien e merçed para ella mandase vuestra magestad se pagase de penas de cámara atentando la proieça de propios e se haría cada año una cofradría de gente noble de dicha villa a la adbocaçión del apóstol Santiago y se haría cada un año el dicho día juegos de cañas y abría una justa e torneos una vez en el dicho año por donde ubiese cunplido e fecho lo que vuestra magestad manda ${ }^{1}$.

Yo Francisco López, escribano del consistorio e ayuntamiento de la dicha villa de Arévalo, por su magestad, fui presente a lo que dicho es y lo fize escrevir; e por mandado y acuerdo del dicho ayuntamiento lo saqué del dicho libro e quaderno e fize mi signo atal. En testimonio de verdad Françisco López (signo) ${ }^{2}$.

Arévalo, 20 de noviembre de 1572.

El corregidor de Arévalo, licenciado Barrientos, pone en conocimiento del rey la reunión y acuerdo tomado por los regidores y caballeros de la villa respecto a la celebración de justas y torneos.

1 Va testado do diz del que. No vala; y en tres renglones escrito, escrivió vala, anotaciones que se refieren al original y no a esta copia.

2 La carta va dirigida A la C. R. M. del rey don Phelipe nuestro señor. La villa de Arévalo. En manos del señor Juan Vázquez de Salaçar. 
S.C. R.M.

Esta villa de Arévalo reçibio una çédula de $V^{\text {a }}$ Magestad fecha de 6 de setienbre refrendada de Juan Vázquez de Salaçar, por la qual Va Magestad manda que esta villa en su regimiento e cabildo con otros caballeros desta villa que para ello se juntasen, tratasen e confiriesen qué orden se tendría para que la cavallería y caballeros se exercitasen en hazer juegos de cañas, justas y torneos, y en recibiendo la dicha cédula e mandato de $V^{a}$ Magestad soios los hize juntar en su cabildo y a él hize llamar algunos cavalleros de la dicha villa y como personas de no mucha espiriençia y celosos de servir a $V^{a}$ Magestad quisieron ver lo que los lugares comarcanos respondian a $V^{a}$ Magestad y ansí responden la orden que les pareçe tendrán en hazer juegos de cañas y justas y torneos y siéndoles mandado por $\mathrm{V}^{\mathrm{a}}$ Magestad, más lo acen como sus leales vasallos cuya muy poderosa persona nuestro Señor guarde con acrecentamiento de maiores reynos y señoríos como los leales vasallos de $\mathrm{V}^{\mathrm{a}}$ Magestad desean.

De Arévalo a 20 de nobienbre de 1572.

\section{S.C.R.M.}

Humilde vasallo de $V^{a}$ Magestad que sus pies besa. El Licenciado Barrientos ${ }^{3}$.

Olmedo, 4 de octubre de $1572^{4}$.

Respuesta del obispo de Ávila a la carta de Felipe II en la que pedía se pusieran en condiciones de defensa las fortalezas del obispado. Tras declarar que sólo posee la fortaleza de Bonilla y que ha gastado en ella una parte considerable de los ingresos de la lglesia, pide se ordene a los súbditos de la sede que colaboren en su mantenimiento.

Diversos de Castilla, leg. 25, fol. 1, págs. $81-84$.

\section{S.C.R.Md.}

Una carta de Vuestra Magestad de VI del pasado recibí en XX del mesmo, y visto lo que por ella Vuestra Magestad me embía a mandar y el sancto zelo con

3 La carta está dirigida A la S. C. R. Magestad del rey don Phelipe nuestro señor, en manos del señor Juan Vázquez de Salaçar, al que ial vez se deba la indicación Arévalo. A su magestad. La Villa a XX de noviembre 1572. Recibida a $23 \mathrm{del}$.

4 La carta va dirigida A la S. C. R. Magestad del Rey don Philippe, nuestro señor. El obispo de Ávila. 4 de octubre 1572; la sobrecarta está dirigida Al llustrísimo señor el señor Juan Vázquez de Salazar, secretario del Magestad y de su mano pueden ser las indicaciones Olmedo. A su Magestad. El obispo de Ávila, 4 de octubre 1572. Recibida 15 del. 
que procura prevenir lo que tanto ymporta para la conservaçión de la sancta yglesia cathólica y Religión christiana que Dios nuestro señor tiene encomendada a Vuestra Magestad como a verdadero protector y defensor della, sólo puedo deçir a Vuesra Magestad que la falta de armas y caballos y aun gente esperimentada en ello es tanta que aunque huviera mucha quantidad de dineros se pudiera mal con lo que Vuestra Magestad mandava por el año de M.D.LXX, y para remediar aora lo que toca a prevenirse de armas y proveerse la fortaleza de Bonilla, ques sola la que tiene esta dignidad y otras cosas, el reparo dellas á sido tanto, después que Vuestra Magestad me hizo merced de proveerme en esta yglesia, con las pensiones, subsidios y escusado y otros gastos de la mesma hazienda viene a ser tan poca la que resta que tengo por muy dificultoso poderse proveer sin ayuda de los súbditos que esta dignidad tiene en las villas y lugares que son della; y esto creo que los tales podrían ayudar por estar más relevados de las cargas que otros.

$Y$ haviendo las dichas armas, la conservaçión y reparo della andará conforme a las demás posesiones de las dignidades.

Yo quisiera harto hallarme con la posibilidad que mi desseo tiene para servir a Vuestra Magestad, pues la obligaçión heredada de tan viejo es tan grande, y la particular de las merçedes que siempre é recibido de Vuestra Magestad.

Guarde y prospere nuestro señor a Vuestra Magestad muchos y muy felices años como estos sus Reynos y la christiandad á menester.

De Olmedo IIII de octubre M.D.LXXII.

De Vuestra Magestad humilde criado y servidor que sus reales manos besa. El Obispo don Álvaro de Mendoza ${ }^{5}$.

Ávila, 13 de septiembre de 1572 .

Respuesta del concejo de Ávila a la real cédula de Felipe II sobre la conveniencia de crear una cofradía de caballeros y ordenar fiestas en las que éstos se ejerciten en las artes militares. En la ciudad existía una cofradía de caballeros puesta bajo la advocación de Santiago, cuya festividad se habia celebrado con grandes fiestas mientras se permitió correr toros: al prohibirse las corridas, la fiesta ha perdido interés y con ella ha disminuido el número de caballeros entrenados y el de caballos por lo que el primer remedio será autorizar de nuevo las corridas.

\footnotetext{
5 La carta va en otra dirigida a Juan Vázquez, con el siguiente texto:

Ilmo. Señor: Una carta de su magestad reçibí los días passados sobre la prebençión de las armas, cuya respuesta va con esta.

Suplico a vuestra merçed la mande dar a su magestad y a mí me manden que le sirva, que lo haré siempre con muy cumplida voluntad.

Guarde nuestro Señor la ilustre prsona de vuestra merced con todo acrezentamiento.

De Olmedo a quatro de octubre 1572.

Servidor de vuestra merçed. El obispo don Álvaro de Mendoça.
} 
Diversos de Castilla, legajo 25, 1, págs. 68-79.

En la muy noble e muy leal çiudad de Ávila, sábado treze días del mes de setienbre del año de quinientos y setenta e dos años, estando en consitorio los muy ylustres señores Justiçia y regidores de la dicha çiudad y canpana tañida según que lo an de huso y de costunbre de se juntar para las cosas tocantes al serviçio de Dios e de su magestad y buena governaçion de la república, estando en el dicho consistorio los ylustres señores Mateo Arévalo Sedeño, corregidor de la dicha Çiudad y de su Tierra por su magestad y Pedro del Águila y Luis Núñez Vela y Diego de Tapia y Françisco de Quiñones e el liçençiado Vergara, regidores de la dicha ciudad, por ante mí Diego de Vega, secretario del dicho consistorio, entre otras cosas que en él se trataron y proveyeron se acordó lo siguiente:

Este día se leyó una carta de su magestad que llegó a la çjudad dando raçon cómo sería servido los cavalleros del reyno se estoviesen encavalgados y con armas y que para esto se juntase la çiudad e algunos cavalleros particulares fuera de los del regimiento para que se comunique la horden que se podrá tener çerca desto y se le enbíe relaçión particular de lo que se acuerda. E vistas las cartas se acordó que se llamen a los cavalleros regidores e algunos de los cavalleros de la çiudad para que oy a las diez oras se junten en la çibdad para tratar y convenir sobre la dicha real carta.

\section{El Rey.}

Conçejo, Justiçia e regidores, cavalleros, escuderos, ofiçiales y onbres buenos de la çiudad de Ávila.

Sabed que algunas personas zelosas de nuestro serviçio...

Y vista la dicha real carta vinieron al dicho consistorio llamados por la çiudad los señores don Rodrigo Dávila, don Diego del Águila, Alonso Vera, don Rodrigo de Águila, Antonio de Vera, don Gaspar del Águila, el comendador Diego de Villalva, Garci Yáñez Móxica, don Josepe de Calatayud, a los quales se les comunicó la dicha real çédula y se platicó y confirió sobrella y se acordó se dé el traslado de la dicha çédula a los dichos cavalleros para que la platiquen, y se cometió a los señores don Diego del Águila e Antonio Vera y el comendador Diego de Villalba e don Rodrigo Dávila e Alonso Vera y don Rodrigo del Águila para que ellos comuniquen con los demás e para el martes primero que traygan resoluçión de su paresçer para que se resporida a su magestad; y señalaron la casa del señor don Rodrigo Dávila donde se juriten dende dos días, después de medio (día) para platicar sobrello. Y las firmas que están al pie del dicho consistorio diçen Mateo Arévalo Sedeño, Gil de Villalva, Diego de Tapia, Luis Núñez Vela, Pedro del Águila, el liçençiado Vergara, Françisco de Quiñones. Pasó ante mí Diego de Vega.

E después de lo susodicho, en la dicha çiudad de Ávila, diez y seis días del mes de setienbre del dicho año, estando en consistorio los muy yllustres señores Justiçia y regidores de la dicha çiudad a canpana tañyda según que lo tienen de huso y de costunbre de se juntar para las cosas tocantes al serviçio de Dios y de su magestad y buena governaçión de la república, estando en el dicho consistorio los yllustres señores Mateo de Arévalo Sedeño, corregidor de la dicha Çiudad y de su Tierra por su magestad y Pedro del Águila y Luis Núñez de Vela e Diego de Tapia y Francisco de Quiñones y don Juan de Ribera y el liçenciado Vergara, 
regidores de la dicha çiudad, por ante mí Diego de Vega, secretario del dicho consistorio, tornándose a conferir sobre la dicha real çédula se hefetuó lo sigu ente:

Vinieron al dicho consistorio los cavalleros a quien el consistorio pasado se cometió comunicasen sobre la çédula de su magestad, exceto el señor don Rodrigo del Águila, y dieron una memoria por escrito de lo que les paresçe çerca de la dicha real çédula el thenor del qual paresçer es el que se sigue:

\section{Paresçer}

Muy Illustre señor.

Paresçe que a causa de aver quitado los toros faltan los cavallos y los regoçijos porque quando los avía se vio en esta çiudad aver muchas fiestas ansí de la gineta como de la brida y muchos cavallos por donde se ve claro que bolviendo los toros bolverán a aver los cavallos y fiestas como solía.

Tanbién paresçe neçesario aparato que de çiudad se tengan tronpetas y atabales, tela y armero porque aviendo esto, en espeçial los toros, en este lugar se tienen por hechas las cofradías y fiestas porque después que los toros se quitaron se vee por espiriençia faltan los cavallos que en esta çiudad solía aver.

Tanbién paresçe que para que los hijosdealgo que no tuvieren armas con que se puedan exerçitar en las (fiestas) ${ }^{6}$ que se hizieren, la çiudad tenga algunos arneses con que se puedan hallar en ellas.

Y para que en todo se cunpla la çédula y mandato de su magestad y las fiestas ayan hefeto, pareçe que V. Señoría mande juntar todo el estado de los cavalleros hijosdealgo y les diga y persuada a que tomando por abogado al señor Santiago hagan en su día para sienpre jamás una fiesta de juegos de cañas y que para esto firmen ante vuestra señoría de sus nonbres, que desde agora fyrmamos nosotros los nuestros aviendo número bastante para que esta cofradía aya hefeto y la fyesta se pueda haçer.

Tanbién paresçe que los cavalleros que aquí no se hallan se les avise y se les pida entren en ella.

Los estatutos y condiçiones que á de tener la dicha cofradía sean los que hordenaren los cavalleros nonbrados por vuestra señoría para este hefeto, añadiendo e quitando de la que en esta çiudad antiguamente à avido quando avíe y se corrían los toros, la qual estava en poder de Ciprián Porrio, escrivano del consistorio.

El número de los cofrades pareçe que sean quarenta porque se puedan reservar algunos caballeros ynpedidos. Don Rodrigo de Valderábanos y Dávila, don Diego del Águila, Antonio de Vera, Alonso Vera, Diego de Villalva.

- El papel ha sido doblado y está roto hacia la mitad por lo que ebtre paréntesis indicamos las palabras que nos parece pudo haber. 
(E después de acabar) los dichos cavalleros de honrar a los dichos señores corregidor y regidores que quedaron, platicaron y confirieron sobrel dicho negoçio y las fyrmas que al pie del dicho consistorio estavan dizen ansí: M. Arévalo Sedeño, Gil de Villaiva, Pedro del Aguila, Françisco de Quiñones, Diego de Cepeda, Luis Núñez Vela, don Juan de Ribera, el liçençiado Vergara. Pasó ante mí Diego de Vega.

E después de lo suso dicho, en la dicha çiudad de Ávila, martes diez y ocho dias del mes de setienbre de myll e quinientos y setenta y dos años, se juntaron en consistorio los mui yllustres señores Justiçia y regidores de la dicha çiudad según que lo an de huso y de costunbre, estando presentes los señores el liçençiado Espinosa, alcalde mayor en la dicha çiudad, Gaspar Dávila y Pedro del Águila y Gil de Villalva y Luis Núñez Vela y don Juan de Ribera y el liçençiado Vergara, regidores de la dicha çibdad, por ante mí el dicho Diego de Vera secretario del dicho consistorio se proveyó entre otras cosas lo siguiente:

Estando en el dicho consistorio se trató y confirió sobre lo que se deve haçer para que la nobleça desta çiudad e cavallería della se hexerçite e aumente y para que se dé respuesta a lo que su magestad tiene ynbiado a mandar en esta su çédula real y lo tratado antes de agora sobrello y el paresçer dado por los cavalleros, los cavalleros hijosdalgo desta çiudad dixeron que era paresçer dellos que para que aya cavallos y cavalleros hexerçitados convenía en cada un año neçesariamente se aga una fiesta de juego de cañas el día de Santiago e que aya toros porque no aviéndolos no puede aver hexerçiçio de cavallos ni regoçijo ni se animarían los cavalleros a tenerlos ni haçer fiestas. E que asimysmo aya de hordinario todo el año puesta tela para que los cavalleros que quisieren justen y se hexerçiten en las armas. Para lo qual e porque quando quisieren tornear lo puedan hacer ay necesidad de tener al respeto una doçena de arneses con todas sus pieças dobles, las quales an destar e sustentarse y linpiarse a costa de la çiudad porque los cavalleros que tienen arneses de suyos no son tantos que basten para poder justar y tornear y aun porque ay muchos hijosdalgo muy actos para estos excerçiçios e por faltarles los aparejos dexarán de enplearse en ello, por lo qual e para el juego de cañas y fiestas hordinaria y estrahordinaria ay neçesidad de música de atabales y tronpetas, que los aya y tenga esta çiudad en ella (armero) para que linpie (...); e proveydo esto déxeles esta çiudad horden como la tiene ya consultada para que se haga una hermandad y colegio de la nobleza y desde luego procurará que entren cavalleros en ella y proveerá esta çiudad el dicho día de Santiago en cada un año a los mysmos cavalleros, mayordomos y ministros que por aquel año se hagan cargo de la cofradía y como se comiençe se yrá entendiendo lo que más conviene proveer e haçer para su perfiçión y se yrá ylustrando con lo que se tiene pero sin duda que en esta çiudad abrá gran copia e aumento de la cavallería porques mucha la nobleça della y toda de hombres muy ynclinados y aparejados al hexerçiçio y mynisterio para lo qual aunque sobre la voluntad y ay hombres nobles e quales conviene al serviçio de su magestad, falta la posibilidad porque la çiudad de suyo no tiene propios que basten a la costa y gastos de sus pleytos e neçesidades hordinarias y tiene mucha neçesidad como paresçe de los recaudos que tiene peresentados en el Consejo Real de su magestad, suplicándole haga merçed de dar de donde pueda remediar y pagar lo que deve; y los cavalleros que pueden sustentar lo neçesario al dicho hexerçiçio y fiesta son pocos y los hijosdalgo a quien falta muchos; por ello y para que lo sobredicho haga hefeto y perpetuidad ay neçesidad, siendo su magestad servido, haga merçed a esta çiudad de su real casa y cámara con lo que fuere servido 
para que comiençe y dé prençipio a lo sobredicho y á de mandar dar liçençia y permytir se puedan correr toros y questa çiudad demás de lo susodicho con liçençia de su magestad pueda haçer renta perpetua hasta en cantía de doçientos ducado que serán menester cada un año para tener, sustentar e haçer lo arriba dicho y lo a ello necesario. E questa renta pueda esta çibdad hecharla e hazerla en aquella e de aquello que con menos daño y más comodidad pueda sacar; con lo qual esta çiudad á resçebido muy gran merçed porque la nobleça della sienpre fue ynclinada a hexerçitarse en la medida y en aquello que le es tan natural a su condiçión para estar como tienen la voluntad y lo harán más avituados y exerçitados para servir a su magestad.

Y esto dixeron que les paresçía se devía haçer y enbiar a su magestad juntamente con lo antes desto tratado y acordado e con el paresçer que sobrello dieron los cavalleros a quien fue cometida la dicha consulta, el qual se ponga al pie deste acuerdo en este libro porque aya raçón dello. E cometióse a los señores Luis Núñez Vela e Gil de Villalva (...). Y las firmas que están al pie del dicho consistorio dizen ansí: el liçençiado Espinosa, Luis Núñez Vela, Pedro del Águila, el liçençiado Vergara. Pasó ante mí Diego de Vega.

E yo el dicho Diego de Vega, escrivano público del número de la dicha Çiudad de Ávila y su Tierra secretario del consistorio de la dicha çiudad por su magestad fui presente a lo que de aquí se haze mençión y de mandamiento del dicho señor alcalde mayor que en esta planta firmó su nombre. El liçençiado Espinosa (signo).

Lo hize escrebir en estas seis hojas de papel de a pliego entero con esta en que va mi signo; e al fin de cada una va mi rúbrica acostunbrada; por tanto hize aquí mi signo atal en testimonio de verdad. Diego de Vega (signo)?

Madrigal, 23 de (septiembre de 1572).

Respuesta del concejo al escrito de Felipe /l pidiendo información sobre las cofradias de caballeros existentes en la villa. Madrigal informa de la existencia de una antigua cofradía que celebraba la fiesta de Santiago corriendo toros a caballo por la villa, y solicita se autoricen de nuevo las corridas y se permita al concejo ayudar económicamente para que las fiestas tengan más realce y puedan los caballeros ejercitarse en su oficio.

Diversos de Castilla, leg. 25, fol. 1, pág. 287

C. R. Magestad.

El conzejo, justiçia y regimiento de la villa de Madrigal, haçiendo a V. Magestad verdadera relaçión de lo que en el cavildo y consistorio de la dicha villa resultó,

Aviéndose conferido y tratado sobre lo que por $\mathrm{V}$. Magestad nos fue mandado por su real zédula sobre la ynstituçión de la confadía para el exerçiçio de armas y cavallería y lo demás conthenido en la dicha real zédula,

7 Sin derechos, añade el texto. 
Diçe que, atenta la dispusiçión desta villa, veçindad y vezinos della y a que en ella ay una antigua confadía de Sanctiago, ques de cavalleros y hijosdealgo, no se entiende que ay nezesidad de otra confadía alguna para más exerçitarse en armas y cavallería porque todos los más cavalleros y hijosdealgo desta villa cada día de Sanctiago salen a cavallo con buen acompañamiento de atabales y pendón de la dicha cofradía y se an acostunbrado a regoçijar a cavallo los dichos días e otros, y aunque después que zesó el correr de los toros no se á continuado tanto como quando se corrían y mataban porque de hordinario se preçiaban muchos a salir bien encabalgados a los dichos toros e quando así los avía jugar cañas por manera que si de aquí adelante $\mathrm{V}$. Magestad fuese servido de mandar dar horden que se corriesen y matasen, el exerçiçio de la dicha cavallería se continuaría más y se entiende yría en abmento y no en diminuçión.

E ansimismo para ello sería muy ymportante y prinçipal que si $V$. Magestad faboreçiese con algunas preminençias o para armas o para cavallos se abmentaría el dicho exerçiçio de armas y cavallería entre los dichos cavalleros e hijosdealgo y otras personas prinçipales que para ello se animarían.

$Y$ para los dichos exerçiçios y requisitos faboreçería mucho que esta villa ayudase de público para dos o tres días cada año como es para música, lanzas, tela y libreas para exerçiçio de justas, torneos, sortija y juegos de cañas; habría de donde lo sacar sin perjuiçio que venga en consideraçión, dando $\mathrm{V}$. Magestad para ello liçençia, porque de propios son tan pocos que para lo susodicho no ay con qué poder ayudar.

Y para que a $V$. Magestad lo susodicho conste se haze esta relaçión por antel presente escrivano del número desta villa y consistorio della.

Yo, Gil González de Hontiveros, escrivano del número y consistorio desta dicha villa de Madrigal ante quien ha pasado lo susodicho, que doy fe como ante mi pasó y queda escrito en el libro de regimiento. Y por mandado del dicho consistorio y de! liçençiado Frías vuestro corregidor en esta villa que aquí firmó hize aquí mi signo. En Madrigal a 23 (ilegible).

El liçençiado Frías (signo). En testimonio de verdad Gil González de Hontiveros (signo). 